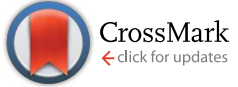

Cite this: RSC Adv., 2017, 7, 7431

Received 7th November 2016

Accepted 2nd January 2017

DOI: $10.1039 / c 6 r a 26436 k$

www.rsc.org/advances

\section{Electrochemical determination of trace pesticide residues based on multiwalled carbon nanotube grafted acryloyloxy ferrocene carboxylates with different spacers $\dagger$}

\begin{abstract}
Feng $\mathrm{Xu}^{*}{ }^{*}$ Zhuo-Miao Cui, He Li and Yan-Ling Luo*
Food safety has always been a topic that attracts attention. The residues of pesticides will directly or potentially affect and threaten human health when they are used to protect crops. Therefore, it is important to rapidly, promptly and accurately monitor pesticide residues in food. In this study, a novel nanohybrid composite with good electrochemical responses was developed, and it was prepared by the esterification reaction of hydroxyl-terminated polybutadiene (HTPB) with MWCNTs-COOH, followed by atom transfer radical polymerization of 4-acryloyloxybutyl(ethyl) ferrocene carboxylates with different spacers. The nanohybrid composites were characterized by FTIR, TGA, Raman, XRD, XPS, SEM and TEM techniques. Cyclic voltammetry (CV) determination showed that a longer spacer between the side ferrocene groups and main chains endowed the electrochemical modified electrodes with active electroresponse, obvious redox current and reversible electrochemical properties because of the faster electron transfer rates. The modified electrode sensor with a longer spacer was used to detect melamine and trichlorfon residues by $\mathrm{CV}$ and differential pulse voltammetry (DPV) techniques. The sensor had a good linear relationship over a wide concentration range, a maximal recovery of ca. $112.4 \%$ and a low detection limit of about $1.5 \times 10^{-7}$ and $3.5 \times 10^{-8} \mathrm{~mol} \mathrm{~L}^{-1}$, respectively.
\end{abstract}

\section{Introduction}

In the recent decades, the need to develop rapid, sensitive and cost-effective pesticide assay techniques to solve the worldwide eco-environmental and food-safety problems has become urgent because food ingredient fraud and organophosphorus pesticide (OP) residues are very serious. ${ }^{1}$ Melamine and trichlorfon are typical examples that are used in a range of products and are being abused for economic interests. These substances cause damage to the ecosystem and human health. For example, melamine, an illegal food adulterant, may cause kidney stones, kidney failure or even death. ${ }^{2}$ High concentrations of melamine were reported in contaminated Chinese infant formula in September, 2008. More than 51900 infants and young children in China were hospitalized for urinary problems, possible renal tube blockages, and kidney stones due to the consumption of the melamine-contaminated infant formula and related dairy products. ${ }^{3}$ OPs, for example trichlorfon, are used widely for agriculture, vector control and domestic purposes as insecticides because of their high activity,

Key Laboratory of Macromolecular Science of Shaanxi Province, School of Chemistry and Chemical Engineering, Shaanxi Normal University, Xi'an 710062, P. R. China. E-mail: luoyanl@snnu.edu.cn; fengxu@snnu.edu.cn; Fax: +862981530727

$\dagger$ Electronic supplementary information (ESI) available. See DOI: $10.1039 / \mathrm{c} 6 \mathrm{ra} 26436 \mathrm{k}$ low bioaccumulation and moderately rapid degradation in the environment. Nevertheless, a certain amount of pesticides migrates from agriculture land and can cause a spectrum of toxic effects on the eco-environment, aquatic organisms and human beings. ${ }^{4}$

Conventional methods to detect melamine in milk and trichlorfon in food and fruits mainly include liquid chromatography (LC), ${ }^{5}$ gas chromatography (GC), ${ }^{6}$ gas chromatographymass spectrometry (GC-MS), ${ }^{7}$ high performance liquid chromatography-diode array detector (HPLC-DAD), ${ }^{8}$ liquid chromatography-mass spectrometry (LC-MS), ${ }^{9}$ etc. Although these methods can give precise analytical data, they require large and expensive instruments, inconvenient utilization, time-consuming analysis, complicated sample treatments, etc. Consequently, it is imperative to explore a new detection method to realize the fast and sensitive determination of melamine and trichlorfon. Electrochemical methods have attracted attention because of their simple design and preparation, low cost, high sensitivity and fast response for determinations. ${ }^{10}$ Various new functional materials are employed to modify electrochemical glass carbon electrodes, and this offers excellent prospects for designing novel detecting systems and enhancing the performance of electrochemical sensors. ${ }^{11}$ Liang et al. ${ }^{12}$ reported a potentiometric sensor based on a molecularly imprinted polymer for melamine detection with a detection 
limit of $1.6 \times 10^{-6} \mathrm{~mol} \mathrm{~L}^{-1}$ that exhibits a short response time and good stability. Ai et al. ${ }^{13}$ took advantage of inter-particle crosslinking of gold nanoparticles to realize the simple and visual detection of melamine, which enables the detection of melamine in raw milk and infant formula at a concentration as low as $2.5 \mathrm{ppb}$ without the aid of any advanced instruments. However, this colorimetric sensor requires a complicated pretreatment to get rid of the interferences in the real samples. Sundarmurugasan et al. ${ }^{\mathbf{1 4}}$ prepared a acetylcholinesterase-zinc oxide modified platinum electrode that was used to simultaneously detect monocrotophos and dichlorvos in orange samples with a detection limit of $1.2 \times 10^{-5} \mathrm{~mol} \mathrm{~L}^{-1}$.

Ferrocene-based polymers are a new class of functional polymers that have attracted significant attention because of their unique redox, electrochemical, mechanical, semiconductive, photophysical, optoelectronic, electronic and magnetic properties. ${ }^{15,16}$ They can be constructed into various systems and devices, and they show important values in academic research and extensive application prospects in the fields of semiconductor materials, phase separation materials, catalysts, redox-responsive drug carriers, biosensors, magnetic ceramic precursors, and smart surfaces, ${ }^{\mathbf{1 7 - 1 9}}$ which is a very active field in functional materials in recent years. Especially, ferrocene groups (Fc) can enhance the electron transfer process between electrode surfaces and immobilized (bio)catalysts, leading to more sensitive and stable (bio)sensors. Modified electrodes comprised of Fc-based polymer films, for instance polyvinylferrocene, have thus gained considerable attention. ${ }^{20}$ The diversity of the side-chain structure and elemental valence states of the ferrocene-based polymers are convenient for manipulating their structure and properties. Li et al. ${ }^{21}$ found that with the increasing length of the side chains, the graft copolymers were difficult to oxidize, and the reversibility of the process was confined. Nevertheless, the chain length influence, especially the length of the spacers between the ferrocene groups in the side chains and main chains, on the electrochemical properties has not been discussed. Multi-walled carbon nanotubes (MWCNTs) show excellent physical, mechanical, electrochemical and optical properties, fast electron transportation, large specific surface areas and strong adsorption. ${ }^{22,23}$ Sensors based on carbon nanotubes have found applications in electrochemical detection of metal ions, pesticides and other pollutants, and these applications have been summarized in detail in a review paper. $^{24}$ These findings motivated us to construct novel nanohybrid composites with increased electrochemical activities combining MWCNTs with ferrocene-based polymers and to fabricate novel electrochemical sensors for the detection of trace pesticide residues.

In this context, our aim is to design and prepare novel MWCNTs and graft polybutadiene-block-ferrocene derivative copolymer nanohybrids by an ATRP approach and fabricate electrochemical sensors for the detection of melamine and trichlorfon residues. The influence of the different lengths of spacers between the ferrocene groups in the side chains and main chains on the electrochemical performance is investigated to more efficiently enhance the charge transfer rate and to acquire excellent electrocatalytic activities. Cyclic voltammetry
(CV) and differential pulse voltammetry (DPV) were employed to determine trace melamine and trichlorfon so as to attain a highly sensitive, simple and quick electrochemical method for the detection of melamine in milk and trichlorfon in fruit and vegetables.

\section{Materials and experiments}

\subsection{Materials and reagents}

Carboxylated multi-walled carbon nanotubes (MWCNTs-COOH, $95 \%$ ), with particle diameters of $10-30 \mathrm{~nm},-\mathrm{COOH}$ content of $3.86 \%$ ( $c a .0 .86 \mathrm{mmol} \mathrm{g}^{-1}$ ), and length of 10-30 $\mu \mathrm{m}$, were provided by the Chengdu Institute of Organic Chemistry, CAS, and dewatered in an oven at $120{ }^{\circ} \mathrm{C}$ before use. Ferrocenecarboxylic acid (FCA, 98\%) and hydroxyl-terminated polybutadiene (HTPB, MW of 2300 and $-\mathrm{OH}$ value of $1.1 \mathrm{mmol} \mathrm{g}^{-1}$ ) were purchased from J \& K Reagent Company, China. 4Hydroxybutyl acrylate (HBA, 98\%) and 2-hydroxyethyl acrylate (HEA, 96\%) were provided by Zahn Chemical Technology Co., Ltd., Shanghai and were used without further purification. 2Bromoisobutyryl bromide (BIB, 98\%), 4-dimethylaminopyridine (DMAP, a highly effective nucleophilic acylation catalyst, 99\%), tetrabutylammonium hexafluorophosphate (TABP, 98\%), and dicyclohexylcarbodiimide (DCC, 99\%) came from the SigmaAldrich (Shanghai) Trading Co., Ltd., China. CuBr (98\%, Aldrich) was purified by stirring overnight in $\mathrm{CH}_{3} \mathrm{COOH}$ at room temperature, followed by washing the solid residues with ethanol, acetone and diethyl ether in sequence, and drying at $40{ }^{\circ} \mathrm{C}$ in vacuo for $24 \mathrm{~h}$. $N, N, N^{\prime}, N^{\prime \prime}, N^{\prime \prime}$-Pentamethyldiethylenetriamine (PMDETA, 98\%) was purchased from the Aladdin (Shanghai) Reagent Company, China and was used without further purification. Triethylamine (TEA, 98\%) was provided by the Tianjin Fuchen Chem Reagent Factory, China and was refluxed over $\mathrm{CaH}_{2}$ for $2 \mathrm{~h}$ and distilled before use. Tetrahydrofuran (THF, 99.5\%), dichloromethane $\left(\mathrm{CH}_{2} \mathrm{Cl}_{2}, 99.5 \%\right), \mathrm{N}, \mathrm{N}$ dimethylformamide (DMF, 99.5\%) were obtained from the Sinopharm Chemical Reagent Co., Ltd., China and were used without further purification. Melamine (99.5\%) and trichlorfon (90\%) were purchased from Tianjin Kermel Chemical Industry Co., Ltd., China. Perfluorinated ion-exchange resin (5\% Nafion solution in aliphatic alcohols/water (85-80/15-20, w/w) mixture) was obtained from the Aladdin (Shanghai) Reagent Company, China. Samples including fresh liquid milk, pear, apple and cucumber were purchased from a local supermarket (Xi'an, China).

\subsection{Synthesis processes}

The synthesis of MWCNTs- $g$-HTPB- $b$-PAEFC and MWCNTs- $g$ HTPB- $b$-PABFC polymers was carried out through a three-step reaction procedure, as shown in Scheme 1. Preparation of the monomers is described in ESI, $\dagger$ and the ${ }^{1} \mathrm{H}$ NMR spectra are shown in Fig. S1.† All experiments for the polymerization reaction were conducted under purified nitrogen with the use of standard Schlenk tubes.

2.2.1 Synthesis of MWCNTs- $g$-HTPB. Dried, crude MWCNTs-COOH (0.02 g, $0.017 \mathrm{mmol})$ were dispersed in $20 \mathrm{~mL}$ 


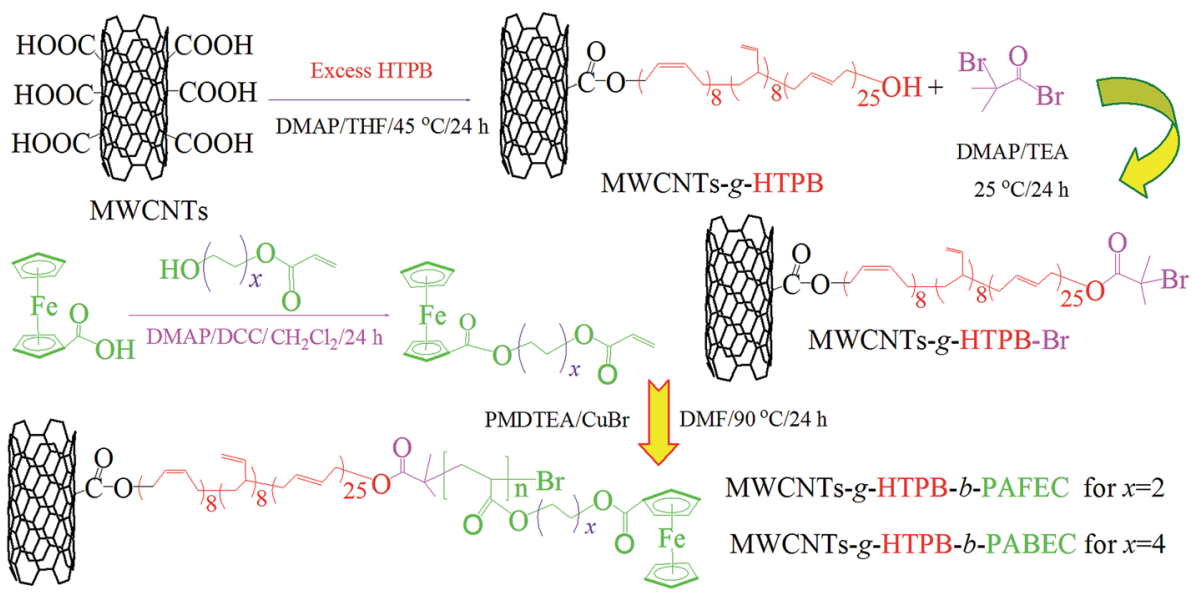

Scheme 1 Synthetic strategies of MWCNTs grafted block copolymer nanohybrid composites.

THF by ultrasonication in a three-neck flask, and then HTPB $(0.07 \mathrm{~g}, 0.085 \mathrm{mmol})$ was added to the flask, followed by $0.002 \mathrm{~g}$ $(0.017 \mathrm{mmol})$ DMAP as the catalyst to obtain a uniform mixed solution. Afterward, $0.035 \mathrm{~g}(0.017 \mathrm{mmol})$ of DCC, the dehydrating agent, was dissolved in $5 \mathrm{~mL}$ of dried THF, and then dropwise added to the mixture at a speed of 3-4 drops per $\mathrm{s}$ at $0{ }^{\circ} \mathrm{C}$ under $\mathrm{N}_{2}$ within $30 \mathrm{~min}$. The solution was stirred at $45{ }^{\circ} \mathrm{C}$ for $24 \mathrm{~h}$ to complete the esterification reaction and then filtered to remove part of DAMP and excess HTPB, thus achieving a solid mixture mainly containing MWCNTs- $g$-HTPB and 1,3dicyclohexylurea (DCU) produced by the reaction of DCC with water. The precipitates were washed with DMF to dissolve the DCU, residual HTPB and DMAP. After filtration, purified MWCNTs- $g$-HTPB were obtained and then flushed with ethanol twice for easier drying in vacuum oven at $60^{\circ} \mathrm{C}$ until a constant weight was reached. A black solid product was obtained with a yield of $95.6 \%$.

2.2.2 Synthesis of MWCNTs-g-HTPB-Br. ${ }^{25}$ The above product was adopted to synthesize initiators for ATRP. Typically, $0.1 \mathrm{~g}(0.043 \mathrm{mmol})$ of the MWCNTs- $g$-HTPB was dispersed in $20 \mathrm{~mL}$ anhydrous $\mathrm{CH}_{2} \mathrm{Cl}_{2}$ for 30 minutes through ultrasonication. Then, $10.6 \mu \mathrm{L}(0.086 \mathrm{mmol}) \mathrm{BIB}$ and $6.6 \mu \mathrm{L}(0.086$ mmol) TEA that had been dissolved in $5 \mathrm{~mL}$ anhydrous $\mathrm{CH}_{2} \mathrm{Cl}_{2}$ were dropwise added to the MWCNTs- $g$-HTPB dispersion solution at a rate of 3-4 drops per $\mathrm{s}$ in an ice water bath under $\mathrm{N}_{2}$ within $30 \mathrm{~min}$. The mixture solution was further stirred at room temperature for $48 \mathrm{~h}$ and then filtered. The solid was washed with $\mathrm{CH}_{2} \mathrm{Cl}_{2}$ and dried in a vacuum oven at $60{ }^{\circ} \mathrm{C}$ for $24 \mathrm{~h}$, affording MWCNTs- $g$-HTPB-Br with a yield of $96.0 \%$.

2.2.3 Synthesis of MWCNTs- $g$-HTPB- $b$-PAEFC and MWCNTs- $g$-HTPB- $b$-PABFC. The MWCNTs- $g$-HTPB- $b$-PAEFC were synthesized by an in situ ATRP polymerization at molar ratios of [initiator] : [monomer] : [ligand] : [catalyst] of $1: 50: 6: 5$. In a typical procedure, $0.02 \mathrm{~g}(0.008 \mathrm{mmol})$ of MWCNTs- $g$-HTPB-Br were added to a $25 \mathrm{~mL}$ dried Schlenk flask and dispersed in $4 \mathrm{~mL}$ DMF for $2 \mathrm{~h}$ under ultrasonication, and then $0.25 \mathrm{~g}(0.4 \mathrm{mmol})$ of AEFC was put into the flask. The reaction system was degassed by vacuum and purging with $\mathrm{N}_{2}$, and $10.2 \mu \mathrm{L}(0.048 \mathrm{mmol})$ PMDETA and $2.0 \mathrm{~mL}$ DMF were then introduced into the mixed solution via a gastight syringe. After a similar degassing operation, $0.0058 \mathrm{~g}(0.04 \mathrm{mmol}) \mathrm{CuBr}$ was put into the Schlenk flask under the protection of $\mathrm{N}_{2}$. The reaction flask was sealed with a rubber plug, and it was further degassed thrice by means of a freezing-pumping-thawing process. The flask was immersed in an oil bath at $90{ }^{\circ} \mathrm{C}$ to start the polymerization. After $48 \mathrm{~h}$, the polymerization was terminated by putting the flask into liquid $\mathrm{N}_{2}$. The reaction mixture solution was vacuum filtered, and the solid was rinsed with DMF thrice. The purified sample was diluted with $\mathrm{CHCl}_{3}$ to replace the residual DMF that remains in the resultant product. After filtering and rinsing with $\mathrm{CHCl}_{3}$ twice, the solid sample was dried in a vacuum oven at $45{ }^{\circ} \mathrm{C}$ overnight, giving MWCNTs$g$-HTPB- $b$-PAEFC (mean yield: $88.4 \%$ ). The MWCNTs- $g$-HTPB- $b$ PABFC were synthesized in the same process and feed ratios as the MWCNTs- $g$-HTPB- $b$-PABFC with a yield of $85.6 \%$. It should be noted that further ultrasonic treatment was conducted to disperse the MWCNTs-g-HTPB-Br after ABFC was put into the flask.

\subsection{Preparation of modified electrode sensors}

The $0.01 \mathrm{~g}$ of the resulting nanohybrid materials was dispersed in $1 \mathrm{~mL}$ chloroform via an ultrasonic technique for $2 \mathrm{~h}$. Homogeneously dispersed conducting composite dispersions $(6 \mu \mathrm{L})$ were uniformly deposited on the clean surface of the pretreated glass carbon electrodes (GCEs, see also ESI $\dagger$ ) using a micro-syringe, and then they were dried with an infrared lamp to obtain finished GCEs coated with the nanohybrid materials. To ensure the proper adherence of the nanostructures on the electrode surface, $5 \mu \mathrm{L}$ of a 1 wt $\%$ Nafion solution was cast on the modified layers and dried before use. The modified electrodes with MWCNTs- $g$-HTPB- $b$-PAEFC and MWCNTs- $g$ HTPB- $b$-PABFC were named MHPEC and MHPBC sensors, respectively.

\subsection{Characterization and measurements}

Fourier transform infrared (FI-IR) spectra were recorded on an EQUINX55 FTIR (Brucker Corp., Germany) using KBr pellets. 
Raman spectra were recorded on an AlMEGA dispersive Raman spectrometer (AlMEGA-TM, Therm Nicolet Corp., USA) using an $\mathrm{Ar}^{+}$laser with an excitation wavelength of $532 \mathrm{~nm}$. Thermal gravimetric analysis (TGA) was carried out on a thermoanalyzer system (Q1000DSC + INCS + FACS Q600SDT, TA Corp., USA) at a heating rate of $10{ }^{\circ} \mathrm{C} \mathrm{min}^{-1}$ under a $\mathrm{N}_{2}$ atmosphere (flow rate: $40 \mathrm{~mL} \mathrm{~min}^{-1}$ ). X-ray diffraction (XRD) patterns were recorded on a D/Max-2550 VB+/PC automatic X-ray diffractometer (Rigaku Corp., Japan) employing $\mathrm{Cu}$ radiation at a voltage of 40 $\mathrm{kV}$, a current of $30 \mathrm{~mA}$, and a scanning rate of $10^{\circ} \mathrm{min}^{-1}$. X-ray photoelectron spectroscopy (XPS) profiles were determined at room temperature on an AXIS ULTRA spectrometer (Kratos Analytical Ltd., Shimadzu Corp., Japan) using a monochromatic Al-K $\alpha$ X-ray source $(1486.6 \mathrm{eV})$ at a voltage of $15 \mathrm{kV}$. A highresolution spectrum was obtained in the peak region of the photoemission for $\mathrm{C} 1 \mathrm{~s}, \mathrm{O} 1 \mathrm{~s}$ and $\mathrm{Fe} 2 \mathrm{p}$ electrons, and the curve fitting of the XPS spectra was performed using the commercially available CasaXPS software.

The morphologies were observed on a transmission electron microscope (TEM, JEM-2100, Electron Corp., Japan) with an accelerating potential of $200 \mathrm{kV}$. Before observation, the samples were ground into powders and sufficiently dispersed in ethyl alcohol by ultrasonication for about $20 \mathrm{~min}$. After that, a drop of the dispersion was dropped on the copper grid with carbon films and dried for 6 h. Scanning electron microscopy (SEM) images were obtained using a SU-8020 field emission electron microscope (FESEM, Hitachi limited Corp., Japan) at an operating voltage of $15 \mathrm{kV}$. All measurements were carried at room temperature.

Electrochemical measurements, including cyclic voltammetry (CV) and differential pulse voltammetry (DPV), were conducted on a CHI 660E electrochemical workstation (Shanghai Chenhua Co., China) with a conventional three-electrode cell, which is composed of bare or modified glassy carbon electrodes (3.0 $\mathrm{mm}$ in diameter) as working electrodes, platinum electrodes as counter electrodes, and saturated calomel electrodes (SCE, 0.2415 V vs. SHE (standard hydrogen electrode)) as reference electrodes. For the detection of melamine, the $\mathrm{CV}$ experiment was performed in a $1 \mathrm{~mol} \mathrm{~L}^{-1} \mathrm{H}_{2} \mathrm{SO}_{4}$ solution at a rate of $50 \mathrm{mV} \mathrm{s}^{-1}$. For the detection of trichlorfon, the DPV measurements were performed in $\mathrm{PBS}$ at $\mathrm{pH}=7$ with a modulation amplitude of $50 \mathrm{mV}$, a pulse width of $50 \mathrm{~ms}$ and a step potential of $5 \mathrm{mV}$.

\subsection{Real sample analysis}

For the detection of residual melamine, the liquid milk was directly spiked with appropriate amounts of a melamine standard solution. Specifically, $500 \mathrm{~mL}$ of $20 \mathrm{mg} \mathrm{L}^{-1}$ melamine in a $1 \mathrm{~mol} \mathrm{~L}^{-1} \mathrm{H}_{2} \mathrm{SO}_{4}$ solution was prepared, and $6.25 \mathrm{~mL}$ of the solution was mixed with $250 \mathrm{~mL}$ of fresh milk to get a $0.50 \mathrm{mg}$ $\mathrm{L}^{-1}\left(3.9 \times 10^{-6} \mathrm{~mol} \mathrm{~L}^{-1}\right)$ melamine solution. The melamine concentration was detected by our electrochemical modified electrodes using cyclic voltammetry.

For the detection of residual trichlorfon, 10 grams of each sample (pear, apple and cucumber) were cleaned and cut into small pieces and added into a $50 \mathrm{~mL}$ beaker. The samples were spiked with PBS standard buffer solutions containing $1 \times 10^{-6}$, $4 \times 10^{-9}$ and $4 \times 10^{-12} \mathrm{~mol} \mathrm{~L}^{-1}$ trichlorfon and immersed for $6 \mathrm{~h}$. The spiked samples were ultrasonicated in $30 \mathrm{~mL}$ of PBS at $\mathrm{pH} 7.0$ for $1-2 \mathrm{~h}$ and filtered to obtain the extracts. The extracts were transferred into a $50 \mathrm{~mL}$ calibrated flask and diluted to the mark with PBS solution. The prepared sample solutions were stored in a refrigerator at $4{ }^{\circ} \mathrm{C}$ and determined by DPV. The recovery percentage and relative standard deviations were determined for 3 different concentrations. Before the measurements, the resulting solutions were filtered through a $0.45 \mu \mathrm{m}$ membrane.

\section{Results and discussion}

\subsection{Structural characterization}

FTIR spectroscopy was used to qualitatively confirm the chemical structure of the MWCNTs grafted block copolymer nanohybrid composites, as shown in Fig. 1(A). For the MWCNTs$\mathrm{COOH}$, a wide and strong peak at $3460 \mathrm{~cm}^{-1}$ is attributed to the stretching vibration mode of the $-\mathrm{OH}$ groups; the peak at $1635 \mathrm{~cm}^{-1}$ is ascribed to the stretching vibration of the $-\mathrm{C}=\mathrm{O}$ in carboxylic acid, and the vibration band at $1573 \mathrm{~cm}^{-1}$ is assigned to the stretching mode of the benzenoid $\left(\nu_{\mathrm{C}=\mathrm{C}}\right)$ in the MWCNTs backbone, indicating the graphite structure of MWCNTs-COOH. ${ }^{26,27}$ After HTPB is grafted from MWCNTs$\mathrm{COOH}$, new and more prominent vibration bands at 1574, 1720 and $3465 \mathrm{~cm}^{-1}$ emerge, which are attributable to the $-\mathrm{C}=$ $\mathrm{C},-\mathrm{C}=\mathrm{O}$ and $-\mathrm{OH}$ stretching modes in $\mathrm{HTPB}$, respectively. It should be noted that the $-\mathrm{OH}$ stretching modes do not completely disappear upon the addition of excess HTPB, which guarantees the existence of end hydroxyl groups, restraint of the possible crosslinking reaction and the preparation of the subsequent ATRP initiators. The structural diagram of the MWCNTs- $g$-HTPB-OH is shown in Scheme 1. The two resulting graft block copolymer nanohybrid materials give identical FTIR spectra because of their almost identical chemical structure. The vibration bands at $3100 \mathrm{~cm}^{-1}$ are attributable to the $-\mathrm{C}=\mathrm{H}$ stretching mode of the ferrocenyl rings; the bands at 2858-2963 $\mathrm{cm}^{-1}$ are ascribed to the $-\mathrm{C}-\mathrm{H}$ stretching; the peaks at 1715 $\mathrm{cm}^{-1}$ are assigned to the ester carbonyl stretching modes; the peaks at $1555 \mathrm{~cm}^{-1}$ are attributed to the $-\mathrm{C}=\mathrm{C}$ stretching modes of the ferrocenyl rings or/and HTPB; the bands at 1134$1275 \mathrm{~cm}^{-1}$ are related to the $-\mathrm{C}-\mathrm{O}$ stretching; and the bands at 773-822 and $485-510 \mathrm{~cm}^{-1}$ reflect the $=\mathrm{C}-\mathrm{H}$ in the ferrocene
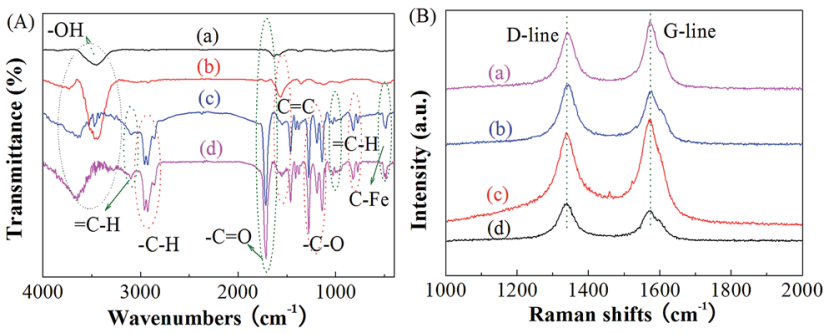

Fig. 1 FTIR (A) and Raman spectra (B) of (a) MWCNTs-COOH, (b) MWCNTs-g-HTPB, (c) MHPEC and (d) MHPBC. 
rings and $\mathrm{Fe}-\mathrm{C}$ or $\mathrm{Cp}-\mathrm{Fe}$ stretching modes, respectively. ${ }^{28}$ These results suggest that $\mathrm{AEFC}$ and $\mathrm{ABFC}$ were chemically attached onto MWCNTs-COOH after ATRP via successful grafting.

Raman spectroscopy was further used to confirm the preparation of the resulting nanohybrid composites, as depicted in Fig. 1(B). The original pristine MWCNTs-COOH exhibit two typical vibration bands at about 1339 and $1574 \mathrm{~cm}^{-1}$, which are assigned to the D- and G-band, respectively. The D band reflects defects and/or disorder-induced $\mathrm{sp}^{3}$-hybridized carbon atoms, whereas the $\mathrm{G}$ band is ascribed to the vibration of the $\mathrm{sp}^{2}$ bonded carbon atoms in a graphitic layer. The relative peak intensity ratio of the $\mathrm{D}$ to $\mathrm{G}$ peak $\left(I_{\mathrm{D}}: I_{\mathrm{G}}\right)$ was calculated to be about 0.95 , signifying that some defects exist in the MWCNTs$\mathrm{COOH}^{29}$ After esterification and the follow-up ATRP, the two main Raman bands in the MWCNTs-COOH remained the same. The $I_{\mathrm{D}}: I_{\mathrm{G}}$ values, however, increased to $1.03,1.08$ and 1.12, respectively, presumably because HTPB, НTPB- $b$-PAEFC or HTPB- $b$-PABFC was covalently linked with the MWCNTs-COOH. Consequently, the HTPB- $b$-PABFC or HTPB- $b$-PAEFC copolymer was chemically grafted onto the surface or/and at the defect dots of the MWCNTs.

The relative amount of AEFC and ABFC grafted onto the MWCNT-COOH was estimated from TGA, as shown in Fig. 2(A). The original pristine MWCNTs-COOH exhibit high thermostability and produce only about $4.6 \%$ mass loss up to $800{ }^{\circ} \mathrm{C}$, which is ascribed to absorbed moisture and ashes..$^{29}$ In the case of the MWCNTs- $g$-HTPB, the mass loss of $c a .3 .3 \%$ at $360{ }^{\circ} \mathrm{C}$ is ascribed to some solvent, DMAP and DCC or DCU residues, and that of $7.4 \%$ from 360 to $500{ }^{\circ} \mathrm{C}$ is related to the decomposition of HTPB on the surface of the MWCNTs-COOH. ${ }^{30}$ For the MWCNTs- $g$-HTPB- $b$-PAEFC, the mass loss of $11.2 \%$ up to $330{ }^{\circ} \mathrm{C}$ results from residual solvents and monomer molecules, and the follow-up mass loss of about $16.3 \%$ from 330 to $800{ }^{\circ} \mathrm{C}$ is attributable to the gradual decomposition of the HTPB and PAEFC backbones covalently attached onto the MWCNTs$\mathrm{COOH}$. The residual amount is about $72.5 \%$, which is ascribed to the MWCNTs and Fe atoms. In contrast, the HTPB- $b$ PAEFC copolymer generates about a $39.3 \%$ mass loss from 330 to $800{ }^{\circ} \mathrm{C}$, and the residues amount for $40.7 \%$. The difference in the residues is about $31.8 \%$. From these data, it was inferred that the relative amount of the HTPB- $b$-PAEFC grafted onto the MWCNTs-COOH was about $57.9 \mathrm{wt} \%$, and the relative amount of the MWCNTs-COOH was ca. $42.1 \mathrm{wt} \%$. Likewise, the relative content of HTPB- $b$-PABFC in the MWCNTs- $g$-HTPB- $b$-PABFC graft copolymer nanohybrids was inferred to be approximately $88.4 \mathrm{wt} \%$, and the relative amount of the MWCNTs-COOH was ca. $11.6 \mathrm{wt} \%$.

Fig. 2(B) shows the XRD patterns of the CNTs graft polymer nanohybrid composites. The original pristine MWCNTs-COOH produce a sharp characteristic diffraction pattern of the graphite structure at $c a .26 .0^{\circ}$ and a weak and wide diffraction at $42.7^{\circ}$ ascribed to the graphite (002) and (100) reflections, respectively. ${ }^{29,31,32}$ After it was associated with HTPB, HTPB- $b$ PABFC and HTPB- $b$-PAEFC through ATRP, the nanohybrid composites possess almost exactly the same characteristic diffraction patterns as the MWCNTs-COOH. Consequently, the covering of the polymers does not affect the graphite structure of the MWCNTs-COOH. The diffraction peaks, however, were found to widen due to the entangling effect of the amorphous polymer molecular chains, which generally produce a broad scattering pattern. In particular, lower diffraction intensities for the MWCNTs- $g$-HTPB- $b$-PABFC emerged, presumably due to the grafting of more amorphous HTPB- $b$-PABFC onto the surface of the MWCNTs-COOH, as described in the TGA analysis. We therefore inferred that the MWCNTs-COOH still existed in their unique graphite structure, and the nanohybrid composites were successfully prepared.

To better confirm the chemical structure in Scheme 1, XPS was used to identify the surface elemental compositions and the chemical valent states of the as-prepared nanohybrid composites, as shown in Fig. 3 and S2 (ESI $\dagger$ ). In the XPS survey spectra of the MWCNTs-COOH in Fig. 3(A), two photoemission peaks at binding energies (BEs) of 285.1 and $532.2 \mathrm{eV}$ were detected, and they are related to the $\mathrm{C} 1 \mathrm{~s}$ and $\mathrm{O} 1 \mathrm{~s}$ signals. ${ }^{30}$ The atomic ratios were 96.0 and $4.0 \%$, respectively. The high-resolution photoemission spectra of the $\mathrm{C} 1 \mathrm{~s}$ signals in Fig. S2(a) (ESI $\dagger$ ) show a dominant peak at $284.5 \mathrm{eV}$ ascribed to $\mathrm{sp}^{2}$-hybridized $\mathrm{C}=\mathrm{C}$ in $\pi$-conjugated systems; a peak at $285.2 \mathrm{eV}$ was assigned to the $\mathrm{sp}^{3}$-hybridized $\mathrm{C}-\mathrm{C}$ bonds at defective locations and the tubular structure asymmetry; a peak at $290.2 \mathrm{eV}$ was ascribed to the $\pi-$ $\pi^{*}$ electronic transition due to a high degree of electron delocalization in the graphitic structure. In addition, three peaks appeared at about 286.2, 287.1 and $288.7 \mathrm{eV}$, which were attributed to the characteristic carbon atoms related to the $\mathrm{C}-\mathrm{O}$, carbonyl groups $(\mathrm{C}=\mathrm{O})$ and carboxylic groups $(-\mathrm{COOH})$ or $\mathrm{O}-$ $\mathrm{C}=\mathrm{O}$, respectively. These findings are consistent with those
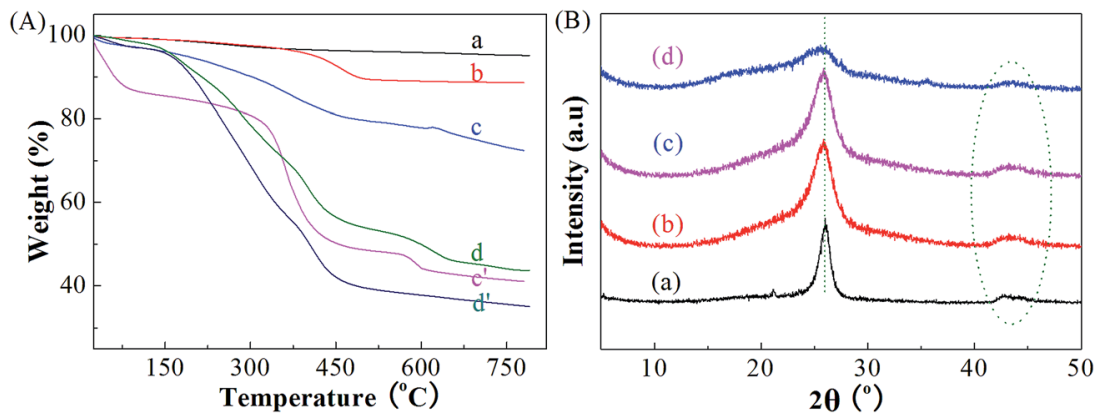

Fig. 2 TGA curves (A) and XRD spectra (B) of (a) MWCNTs-COOH, (b) MWCNTs-g-HTPB, (c) MHPEC, (c') HTPB- $b-P A E F C$, (d) MHPBC, and (d') HTPB- $b$-PABFC. 

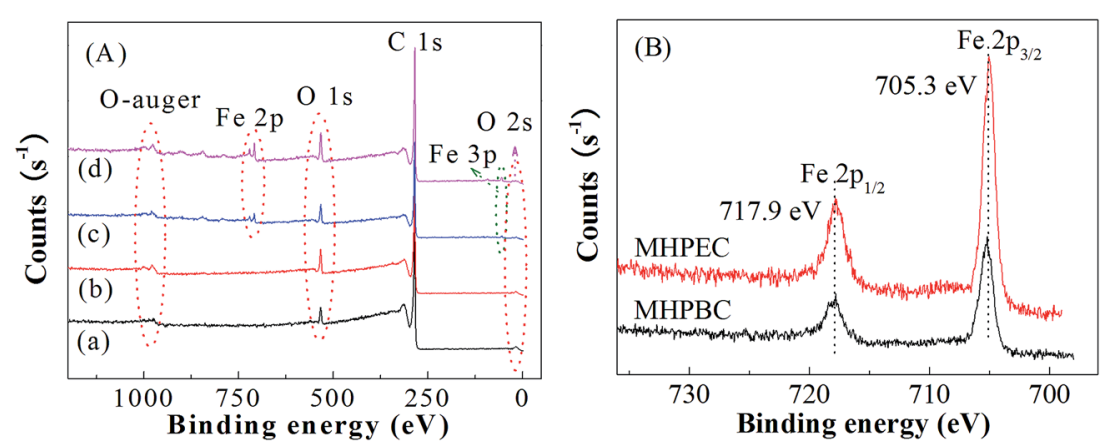

Fig. 3 (A) Wide-survey XPS spectra of (a) MWCNTs-COOH, (b) MWCNTs- $g$-HTPB, (c) MWCNTs-g-HTPB- $b$-PABFC (MHPBC) and (d) MWCNTs$g$-HTPB- $b$-PAEFC (MHPEC) nanohybrid composites; and (B) high-resolution XPS spectra of Fe 2p in typical MHPBC and MHPEC nanohybrid composites.

reported in the literature. ${ }^{33,34}$ The $\mathrm{O} 1 \mathrm{~s}$ core-level spectrum in Fig. S2(b) of the ESI $\dagger$ shows the existence of the oxidation peaks associated with the $\mathrm{C}-\mathrm{O}$ and $\mathrm{C}=\mathrm{O}$ bonds at 532.3 and $533.5 \mathrm{eV}$, respectively. These types of oxygen-containing functional moieties on MWCNTs offers possibilities for surface chemical modifications.

After the HTPB oligomers were grafted onto the surface of the MWCNTs, no new elemental peaks appeared except the C 1s and $\mathrm{O} 1 \mathrm{~s}$ signals, but the peak intensities and atomic ratios changed. The atomic ratios of $\mathrm{C}$ and $\mathrm{O}$ elements were 93.2 and 6.8\%, respectively (Fig. 3A(b), and Table S1 in ESI $\dagger$ ). Furthermore, in the $\mathrm{C} 1 \mathrm{~s}$ and $\mathrm{O} 1 \mathrm{~s}$ core-level spectra in Fig. S2(c) and (d) in the ESI, $\uparrow$ new signals emerged at the BEs of about 287.6 and $531.9 \mathrm{eV}$, revealing the presence of chemically different $\mathrm{C}$ and $\mathrm{O}$ species attributed to the $-\mathrm{C}-\mathrm{O}-\mathrm{H}$ bonds of the terminal hydroxyl groups in the HTPB moieties. This differs from the $\mathrm{O} 1 \mathrm{~s}$ and $\mathrm{C}$ 1s signals in the MWCNTs- $\mathrm{COOH}$, implying the grafting of HTPB on the surface of the MWCNTs. For the MHPBC and MHPEC nanohybrid composites in Fig. 3A(c) and (d), new element signals assigned to the electrons emitted from the $\mathrm{Fe}$ $2 \mathrm{p}$ and Fe $3 \mathrm{~s}$ levels at BEs of about 708.4-720.7 and $56.1 \mathrm{eV}$ in addition to the $\mathrm{C} 1 \mathrm{~s}$ and $\mathrm{O} 1 \mathrm{~s}$ levels were observed. The emergence of the $\mathrm{Fe}$ signals gives evidence for the presence of ferrocene-containing moieties such as PABFC or/and PAEFC on the MWCNT surfaces. MHPEC possesses increased Fe and $O$ atomic ratios but a decreased $\mathrm{C}$ amount in comparison with MHPBC, as summarized in Table S1 of the ESI, $\dagger$ which is consistent with their respective molecular structures. The Fe 2p core-level XPS spectra in Fig. 3(B) clearly show that the Fe 2p peaks are deconvoluted into a spin-orbit-coupled doublet with the BEs of $c a .705 .3$ and $717.9 \mathrm{eV}$, which is ascribed to the electrons from the $\mathrm{Fe} 2 \mathrm{p}_{3 / 2}$ and $\mathrm{Fe} 2 \mathrm{p}_{1 / 2}$ electronic levels, respectively, in agreement with those of the ferrocene derivatives. ${ }^{35,36}$ The C 1s core-level spectra in Fig. S2(e) and (g) of the ESI $\dagger$ display several different $\mathrm{C}$ species, and their BEs are approximately 284.5-284.6, 284.8, 285.2-285.3, 286.3, 287.0, 288.6-288.7 and 289.6-289.8 eV assigned to the $\mathrm{C}=\mathrm{C}$, ferrocenyl carbons (C-Fe), $\mathrm{C}-\mathrm{C}, \mathrm{C}-\mathrm{O},(\mathrm{R}-) \mathrm{C}=\mathrm{O}, \mathrm{O}-\mathrm{C}=\mathrm{O}$ and $\pi-\pi^{*}$ electronic transition, respectively. ${ }^{36-38}$ The larger peak areas of the $\mathrm{C}-\mathrm{C}$ signals than the $\mathrm{C}=\mathrm{C}$ signals are consistent with the incorporation of more $\mathrm{C}-\mathrm{C}$ bonds in the ferrocene-containing blocks. The O 1s core-level spectra disclose the presence of two types of chemically different $\mathrm{O}$ species at the BEs of about 532.6-532.8 and 533.9-534.0 eV, which are attributed to the C-O and $\mathrm{C}=\mathrm{O}$ bonds from the ester groups, as shown in Fig. S2(f) and (h) in the ESI. $\dagger$ These results suggest that the ferrocenecontaining copolymer moieties were grafted onto the surface of the MWCNTs-COOH, forming the MHPBC and MHPEC nanohybrid composites.

To investigate the morphologies of the prepared nanohybrid composites, SEM observations were made, as shown in Fig. 4. The pure MWCNTs-COOH showed a smooth and randomly entangled surface morphology in clusters. After the surface graft reaction with HTPB and HTPB- $b$-PABFC or HTPB- $b$-PABFC, the polymer layers were found to closely cover the surface of the MWCNTs or around the MWCNTs, forming an organic whole connected by the graft polymers. The tubes thickened at different levels, ranging from 3 to $15 \mathrm{~nm}$, because the polymer layers with various chain lengths covered the MWCNTs surface. The encapsulation of these polymers on the surface of the MWCNTs was further observed by TEM, as displayed in Fig. 5 . The crude MWCNTs-COOH had outer diameters between 10 and $30 \mathrm{~nm}$, and the wall surface was smooth, without any detectable amorphous layers except for several blobs of amorphous carbon. The TEM images of the MWCNTs- $g$-HTPB- $b$ PAEFC and MWCNTs- $g$-HTPB- $b$-PABFC clearly show that the surface of the MWCNTs-COOH is covered with amorphous polymer layers with a slightly shallower color. The MWCNTs$\mathrm{COOH}$ layers were thicker by $3-8 \mathrm{~nm}$, and the tubular diameters increased up to $30-38 \mathrm{~nm}$. Considering that the HTPB- $b$ PAEFC and HTPB- $b$-PABFC polymer layers are covalently linked to the MWCNTs-COOH, the polymers will be left on the surface of the MWCNTs after the washing operation is completed. Therefore, the HTPB- $b$-PAEFC and HTPB- $b$-PABFC copolymers are indeed chemically grafted onto the surface of the MWCNTs$\mathrm{COOH}$.

\subsection{Electrochemical characteristics}

$\mathrm{CV}$ is a popular and important technique for the study of electrochemistry and has proven to be very useful in obtaining thermodynamic and kinetic information of electrochemical 

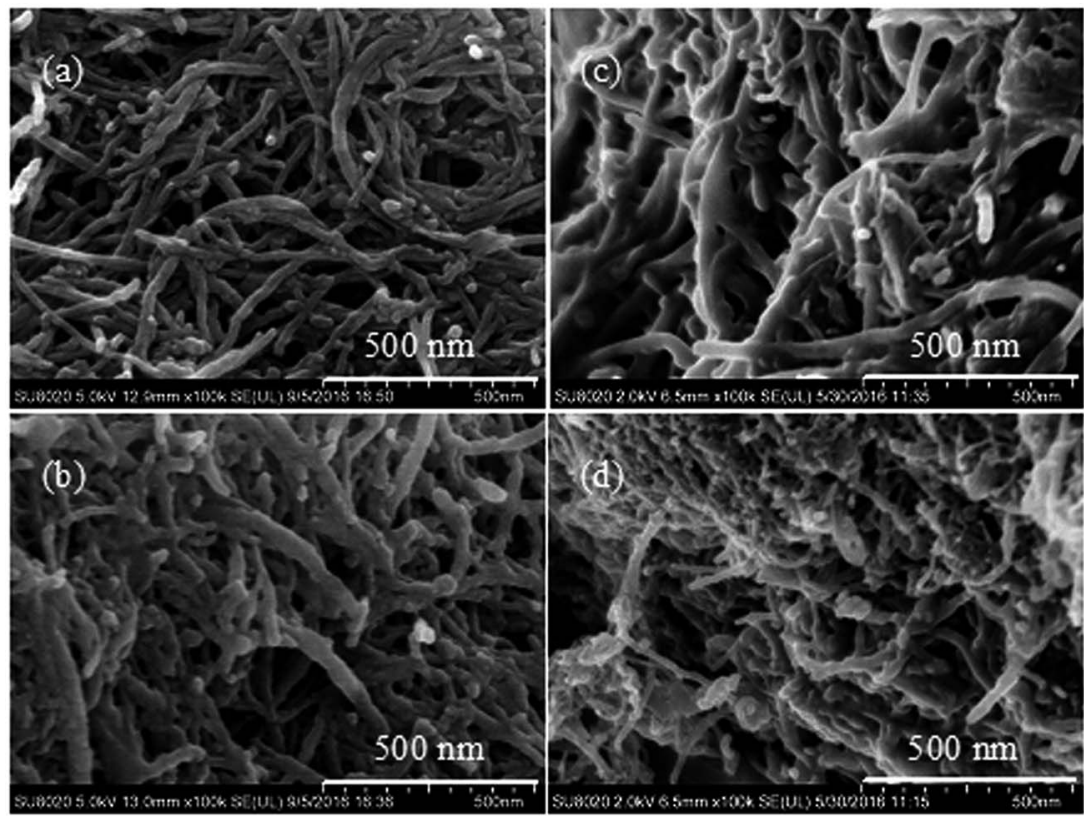

Fig. 4 FESEM morphologies of (a) MWCNTs-COOH, (b) MWCNTs-g-HTPB, (c) MHPBC and (d) MHPEC nanohybrids.
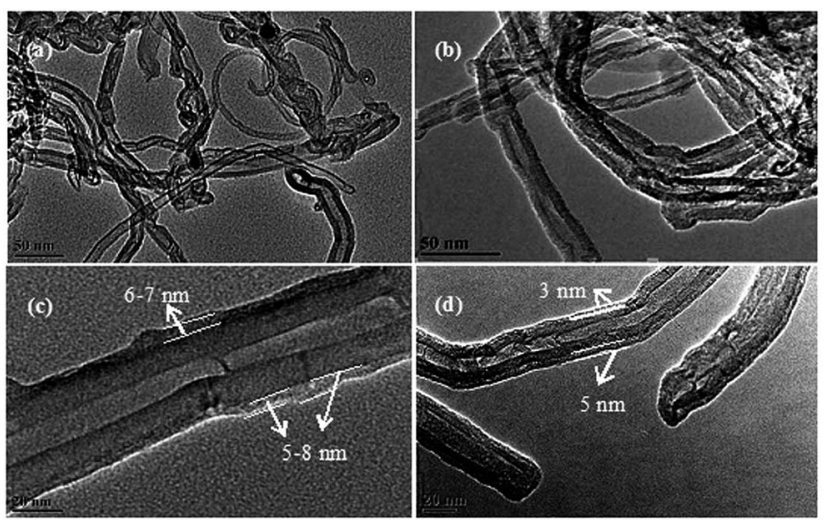

Fig. 5 TEM images of (a) MWCNTs-COOH, (b) MWCNTs-g-HTPB, (c) MHPBC, and (d) MHPEC nanohybrids.

reactions such as the peak potentials and reaction rates. ${ }^{39}$ The electrochemical properties of the MWCNTs grafted polymer modified electrodes with different chain length spacers (ethyl and butyl groups) between the main chains and ferrocene groups were investigated, as depicted in Fig. 6(A). Clearly, the bare GCE and the modified GCE electrode coated with the MWCNTs-COOH failed to generate any obvious redox response. In contrast, the HTPB- $b$-PAEFC/GCE and HTPB- $b$-PABFC/GCE modified electrodes produced well-defined and quasireversible redox peak currents and small peak potential differences or peak separation $\Delta E\left(\Delta E_{\mathrm{p}}=E_{\mathrm{p} \text {,anodic }}-E_{\mathrm{p} \text {,cathodic }}\right)$ lower than $115 \mathrm{mV}$, which was ascribed to the reversible $\mathrm{Fe}(\mathrm{III}) / \mathrm{Fe}(\mathrm{II})$ redox process. ${ }^{40}$ Particularly, the HTPB- $b$-PABFC/GCE sensor produced stronger redox peak currents than the HTPB- $b$ PAEFC/GCE one. This signifies that the HTPB- $b$-PABFC/GCE electrode accelerates the electron transfer rates more than
HTPB- $b$-PAEFC/GCE, which is beneficial for the redox reaction between active substances. The MHPBC modified electrode was found to produce more obvious current responses than the HTPB- $b$-PABFC/GCE counterpart, presumably due to a synergetic effect induced by the two constituents, the ferrocene moieties and MWCNTs. Although the $\Delta E$ remains almost the same, ranging from 220 to $218 \mathrm{mV}$ as the length of the spacers increases, the redox peak current significantly increased from the MHPBC to MHPEC electrodes, and the symmetry of the CV curves was enhanced. Therefore, the modified electrode with a longer spacer exhibited more reversible electrochemical properties. The possibility is that the longer spacer for the MHPBC modified electrode decreases the disturbance against the ferrocene moieties and facilitates electron transfer at the electrode interface. ${ }^{21,41,42}$ In fact, the electrical resistance measurements in Table S2 of the ESI $\dagger$ show that the long chain MHPBC modified electrode sensor has a higher electric conductivity than the short chain MHPEC one, greatly increasing the conduction of the electrons. Therefore, it was concluded that the MHPBC modified electrode with a longer spacer is anticipated to be able to fabricate an electrochemical sensor.

Considering that the scan rate may affect the electroactivity of the nanohybrid materials or the conducting rate of the electrons, ${ }^{43}$ the effect of the scan rate on the $\mathrm{CV}$ profiles was examined, as shown in Fig. 6(B). It can be seen that with the increasing scan rates, the oxidation peak currents strengthened, and the oxidation peak potentials moved slightly in the positive direction. The peak currents were directly proportional to the scan rate in the range from 20 to $120 \mathrm{mV} \mathrm{s}^{-1}$, exhibiting a good linear relationship between the scan rates and peak currents and giving a well-defined linear equation $I_{\mathrm{p}, \mathrm{a}}\left(10^{-5} \mathrm{~A}\right)=$ $0.0720 \nu\left(\mathrm{mV} \mathrm{s}^{-1}\right)+4.1587\left(R^{2}=0.9924\right)$, as illustrated in the 

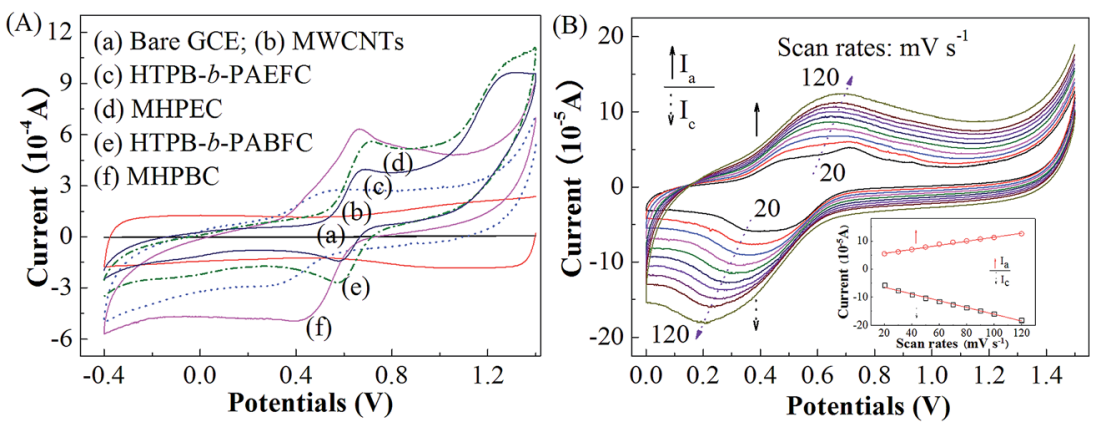

Fig. 6 (A) CVs of (a) bare GCE, and GCE coated with (b) MWCNTs, (c) HTPB-b-PAEFC, (d) MHPEC, (e) HTPB-b-PABFC and (f) MHPBC in acetonitrile with $0.1 \mathrm{M}$ tetrabutylammoniumperchlorate (TBAP) at a scan rate of $50 \mathrm{mV} \mathrm{s}^{-1}$; and (B) CVs of the MHPBC modified electrodes in a $1 \mathrm{M} \mathrm{H}_{2} \mathrm{SO}_{4}$ solution at various scan rates. The scan rate is $20,30,40,50,60,70,80,90,100$ and $120 \mathrm{mV} \mathrm{s}^{-1}$ in order of the arrows. The inset shows the dependence of the peak currents on the scan rates.

inset of Fig. 6(B). The cathodic peak current $\left(I_{\mathrm{p}, \mathrm{c}}\right)$ dependence on the scan rates had similar patterns, offering a linear equation of $I_{\mathrm{p}, \mathrm{c}}\left(10^{-5} \mathrm{~A}\right)=-0.12027 \nu\left(\mathrm{mV} \mathrm{s}^{-1}\right)-4.0874\left(R^{2}=\right.$ 0.9910). These findings suggested that the oxidation and reduction were a diffusion-controlled electrode reaction process for the MHPBC sensor, and the electrode processes are quasireversible. ${ }^{44}$

\subsection{Electrochemical detection of melamine and trichlorfon}

In consideration of the excellent electrochemical responses of the MHPBC modified electrode sensor, it was expected to detect melamine and trichlorfon residues.

3.3.1 Electrochemical determination of melamine. Fig. 7(A) compares the electrochemical response of the MHPBC modified sensors in $1 \mathrm{M} \mathrm{H}_{2} \mathrm{SO}_{4}$ without and with $1 \times 10^{-3} \mathrm{~mol}$ $\mathrm{L}^{-1}$ melamine. It was noticed that the two pairs of modified electrodes possessed almost the same peak-to-peak potential differences $\left(\Delta E_{\mathrm{p}}\right)$ of $c a .0 .260 \mathrm{~V}$ for $10^{-3} \mathrm{M}$ melamine and $0.220 \mathrm{~V}$ for $0 \mathrm{M}$ melamine. However, the anodic and cathodic redox peak currents were different, and the MHPBC modified electrode sensor had a stronger current response to the $1 \mathrm{M}$ $\mathrm{H}_{2} \mathrm{SO}_{4}$ solution of $1 \times 10^{-3} \mathrm{~mol} \mathrm{~L}^{-1}$ melamine than that without melamine. However, for the MHPEC sensor, as demonstrated in Fig. S3 of the ESI, $\uparrow$ almost completely overlapped CV profiles emerged, including the $\Delta E_{\mathrm{p}}$ and redox peak currents, without a special response to melamine. Therefore, the extraordinary electroactivity of the MHPBC sensor can be used as an analytical signal to detect melamine, providing an improved electroanalytical response for melamine residues in milk.

To detect trace melamine, calibration curves were prepared using CV, and the results are shown in Fig. 7(B). The redox peak currents were linearly dependent on the concentrations of melamine over a wide range of $1 \times 10^{-3}$ to $1 \times 10^{-9} \mathrm{M}$. The oxidation peak current $\left(I_{\mathrm{p}, \mathrm{a}}\right)$ was proportional to the logarithm of the melamine concentration $\left(C_{\mathrm{Mel}}\right)$. The linear equation can be expressed as $I_{\mathrm{p}, \mathrm{a}}\left(10^{-5} \mathrm{~A}\right)=2.04 \lg C_{\mathrm{Mel}}+25.25$, with the correlation coefficient 0.9632 , whilst the reduction current $\left(I_{\mathrm{pc}}\right)$ and the logarithm of the melamine concentration show a good linear relationship in a concentration range from $1 \times 10^{-3}$ to $1 \times$ $10^{-9} \mathrm{M}$ with the linear calibration equation $I_{\mathrm{p}, \mathrm{c}}\left(10^{-5} \mathrm{~A}\right)=$ $-2.69 \lg C_{\mathrm{Mel}}-33.82\left(R^{2}=0.9319\right)$. The limit of detection (LOD) is estimated using three times the noise, viz., signal/noise $=3$, together with the following equation as reported elsewhere: ${ }^{45}$

$$
\mathrm{LOD}=K S_{\mathrm{b}} / r
$$

where $S_{\mathrm{b}}$ is the standard deviation of the signals; $K$ is a coefficient determined based on a certain confidence level factor
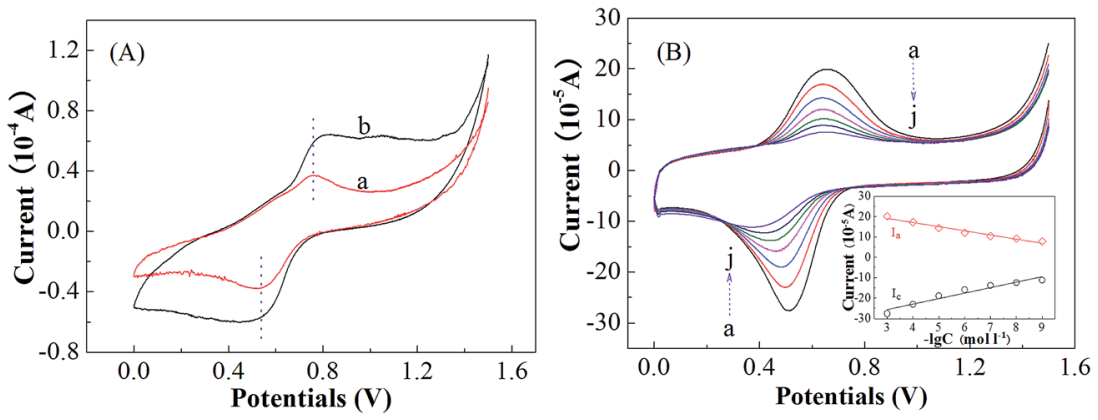

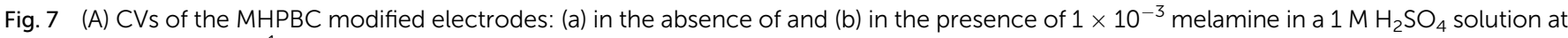
a scan rate of $50 \mathrm{mV} \mathrm{s}^{-1}$; (B) CVs of the MHPBC modified electrodes in a $1 \mathrm{M} \mathrm{H}_{2} \mathrm{SO}_{4}$ solution for various melamine concentrations expressed as mol L ${ }^{-1}: 1 \times 10^{-3}, 1 \times 10^{-4}, 1 \times 10^{-5}, 1 \times 10^{-6}, 1 \times 10^{-7}, 1 \times 10^{-8}$ and $1 \times 10^{-9}$ at a scan rate of $50 \mathrm{mV} \mathrm{s}^{-1}$. The inset shows calibration curves for the determination of melamine. 
$(K=3)$; and $r$ is the sensitivity of the method, namely, the slope of the calibration curve. The LOD is $1.5 \times 10^{-7} \mathrm{~mol} \mathrm{~L}^{-1}(1.9 \times$ $10^{-2} \mathrm{mg} \mathrm{L}^{-1}$ ), which is low enough for the determination of trace melamine in real sample analysis. ${ }^{12}$ The low LOD can be used for highly-sensitive detection of trace melamine, much lower than the melamine safe standard released by many countries, including the World Health Organization (WHO). The Codex Alimentarius Commission (CAC) rules that the maximum residue levels for melamine are $1 \mathrm{mg} \mathrm{L}^{-1}$ in infant formula and $2.5 \mathrm{mg} \mathrm{L}^{-1}$ in other milk-based products and foods.

To determine the feasibility and reproducibility of the proposed technique, the MHPBC sensor was independently examined under the same conditions by analyzing the residues of melamine in real milk. The $I_{\mathrm{p}, \mathrm{a}}$ was determined to be $13.51 \times$ $10^{-5} \mathrm{~A}$ (Fig. S4 of ESI $\dagger$ ), and the concentration of melamine was calculated to be about $1.72 \times 10^{-6} \mathrm{~mol} \mathrm{~L}^{-1}$ using the equation $I_{\mathrm{p}, \mathrm{a}}\left(10^{-5} \mathrm{~A}\right)=2.04 \mathrm{lg} C_{\mathrm{Mel}}+25.25$, with a relative standard deviation (RSD) of $2.3 \%$ for 9 independent determinations, indicating that the method is feasible and repeatable. The proposed method is also simple and environmentally friendly because it needs no complex subsequent procedures like centrifugation and filtration. The durability or lifetime of the method was examined using the change in the peak currents with time, as shown in Fig. S5 of the ESI. $\dagger$ It was found that the recovery rate of the peak currents was 91.8 and $85.8 \%$ with an RSD of 3.98 and $9.98 \%$ after 7 and 30 days, respectively. In particular, the peak currents after the second day remained almost unchanged, indicating good stability.

3.3.2 Electrochemical determination of trichlorfon. The electrochemical technique can also be used to quantitatively detect trichlorfon residues, and this was performed by DPV, which is more sensitive than the conventional CV method. ${ }^{46}$ The long-term stability or lifetime as an important indicator was examined by determining the change in the DPV profiles at a fixed trichlorfon concentration of $1 \times 10^{-8} \mathrm{~mol} \mathrm{~L}^{-1}$ using the same electrode during storage in air for 30 days, as depicted in Fig. S6 in the ESI. $\uparrow$ Clearly, the modified electrode hardly produced a decrease in the peak currents. After one week and 30 days, more than 99.6 and $98.5 \%$ of the initial values were still produced, and the current response only deviated by about 2.88 and $1.67 \%$, respectively. The repeatability of the amperometry measurement of the MHPBC modified electrode sensors was examined in a solution of $1 \times 10^{-12} \mathrm{~mol} \mathrm{~L}^{-1}$ trichlorfon, and the mean peak current for five measurements at the same concentration using the same electrode was $-1.643 \mu \mathrm{A}$ with an RSD of $-0.603 \%$, as illustrated in Fig. S7(a) of the ESI. $\dagger$ To study the reproducibility of the fabrication process of the modified electrodes, five MHPBC modified electrode sensors were individually prepared in the same manner and applied for trichlorfon determination with an RSD of approximately 3.3\% (Fig. S7(b) in the ESI $\dagger$ ). These findings indicate that the modified electrode has a high stability and repeatability and excellent reproducibility.

In this study, all the experiments were carried out in a conventional electrochemical cell containing $10 \mathrm{~mL}$ of a $0.2 \mathrm{~mol} \mathrm{~L}^{-1}$ PBS buffer solution $(\mathrm{pH}=7.0)$ with various concentrations of trichlorfon from $1.0 \times 10^{-5}$ to $1.0 \times$ $10^{-10} \mathrm{~mol} \mathrm{~L}^{-1}$ and from $5.0 \times 10^{-12}$ to $3 \times 10^{-13} \mathrm{~mol} \mathrm{~L}^{-1}$ at room temperature, as shown in Fig. 8. Under the chosen experimental conditions, the linear regression equations can be expressed as $I_{\mathrm{p}, \mathrm{a}}(\mu \mathrm{A})=0.26(-\lg C)-4.41\left(R^{2}=0.9899\right)$ and $I_{\mathrm{p}, \mathrm{c}}$ $(\mu \mathrm{A})=0.096(-\lg C)-2.76\left(R^{2}=0.9941\right)$, respectively. The LOD was estimated to be approximately $3.5 \times 10^{-8} \mathrm{~mol} \mathrm{~L}^{-1}(9.0 \times$

Table 1 Experimental data of trace trichlorfon in real samples determined by DPV

\begin{tabular}{llllr}
\hline Sample & $\begin{array}{l}\text { Added } \\
\left(10^{-7} \mathrm{~mol} \mathrm{~L}^{-1}\right)\end{array}$ & $\begin{array}{l}\text { Found }^{a} \\
\left(10^{-7} \mathrm{~mol} \mathrm{~L}^{-1}\right)\end{array}$ & $\begin{array}{l}\text { RSD } \\
(\%)\end{array}$ & $\begin{array}{l}\text { Recovery } \\
(\%)\end{array}$ \\
\hline \multirow{2}{*}{ Pear } & 0.4 & 0.41 & 3.6 & 101.5 \\
& 2.0 & 1.68 & 2.3 & 82.0 \\
\multirow{4}{*}{ Apple } & 3.5 & 3.26 & 0.7 & 93.1 \\
& 0.4 & 0.37 & 6.1 & 93.5 \\
\multirow{4}{*}{ Cucumber } & 2.0 & 1.77 & 8.1 & 88.5 \\
& 3.5 & 3.93 & 0.8 & 112.4 \\
& 0.4 & 0.38 & 6.3 & 95.0 \\
& 2.0 & 1.81 & 0.9 & 90.5 \\
& 3.5 & 3.37 & 0.6 & 96.2
\end{tabular}

${ }^{a}$ Represents the mean value of five measurements in this experiment.
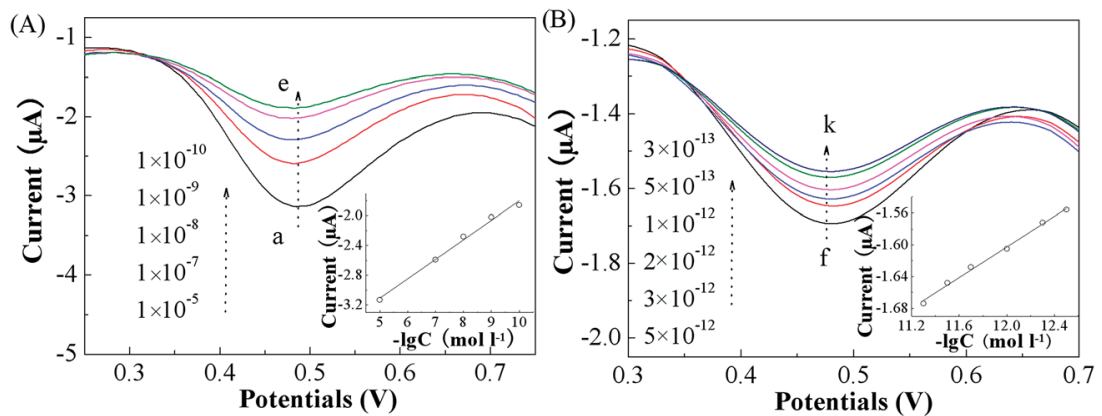

Fig. 8 DPV curves of MHPBC modified electrodes for the detection of trichlorfon with a concentration range $\left(\mathrm{mol} \mathrm{L}^{-1}\right)$ : (A) $1 \times 10^{-5}, 1 \times 10^{-7}, 1$ $\times 10^{-8}, 1 \times 10^{-9}$, and $1 \times 10^{-10}$ corresponding to (a) to (e), and (B) $5 \times 10^{-12}, 3 \times 10^{-12}, 2 \times 10^{-12}, 1 \times 10^{-12}, 5 \times 10^{-13}$, and $3 \times 10^{-13}$ from (f) to (k), in PBS at pH 7.0 at a scan rate of $50 \mathrm{mV} \mathrm{s}^{-1}$. The insets show the linear relationship between the peak currents $\left(I_{\mathrm{p}}\right)$ and trichlorfon concentrations. 
$10^{-3} \mathrm{mg} \mathrm{L}^{-1}$ ), a significantly lower LOD in comparison with other techniques. ${ }^{\mathbf{1 4}, \mathbf{4 7 - 4 9}}$ It was therefore concluded that the prepared electrochemical sensor exhibits remarkable advantages with a high sensitivity, wide linear range and low LOD.

To evaluate the applicability of the MHPBC sensor, pear, apple and cucumber samples immersed in trichlorfon were prepared, and the trichlorfon residues were detected by DPV under the chosen conditions. Each sample was measured five times and averaged, and the results are given in Table 1. It was seen that the MHPBC sensors gave similar data between the determined amount and the added amount of trichlorfon in pear, apple and cucumber samples with low RSDs of $0.7-3.6 \%$, $0.8-8.1 \%$ and $0.6-6.3 \%$ and high recoveries of $82.0-101.5 \%$, 93.5-112.4\% and $90.0-96.2 \%$ for pear, apple and cucumber, respectively. Consequently, the developed MHPBC modified electrode sensor proved to be a promising and reliable tool for the rapid and simple determination of trichlorfon residues in real samples.

\section{Conclusion}

In conclusion, we have demonstrated an efficient approach to prepare novel carbon nanotube grafted block copolymer nanohybrid composites, MHPBC and MHPEC, as confirmed by FTIR, Raman, XRD, XPS and TGA measurements. The MHPBC modified electrodes with longer side chains or spacers between the side ferrocene groups and main chains exhibited good electrochemical responses and quasi-reversibility because of the easier electron transfer at the electrode interface. The MHPBC electrochemical modified electrodes had good reproducibility, stability and a linear relationship over a wide concentration range. A significantly low detection limit of $3.5 \times$ $10^{-8} \mathrm{~mol} \mathrm{~L}^{-1}$ allows us to detect trace melamine and trichlorfon residues in food or fruits. Therefore, the newly developed nanohybrid composites can potentially be fabricated into novel electrochemical sensors for applications in the inspections of food safety.

\section{Acknowledgements}

This work is supported by the National Natural Science Foundation of China (grant 21572123, 21273142 and 21172138) and the Fundamental Research Funds for the Central Universities (GK201601003).

\section{References}

1 L. F. M. C. Aquino, A. C. O. Silva, M. Q. Freitas, T. L. Felicio, A. G. Cruz and C. A. Conte-Junior, Food Res. Int., 2014, 62, 233-237.

2 J. L. Dorne, D. R. Doerge and M. Vandenbroeck, Toxicol. Appl. Pharmacol., 2013, 270, 218-229.

3 M. S. Filigenzi, B. Puschner, L. S. Aston and R. H. Poppenga, J. Agric. Food Chem., 2008, 56, 7593-7599.

4 R. Basanta, A. Nuñez, E. Lopez, M. Fernandez and F. DiazFierros, Int. J. Environ. Stud., 2007, 48, 211-219.
5 J.-D. Yang, X. W. Sun, Z. J. Feng, D. F. Hao, M. Q. Wang, X. J. Zhao and C. D. Sun, Toxicol. Lett., 2011, 206, 306-313.

6 L. Amendolaa, F. Botrèb, A. S. Carolloa, D. Longoa and L. Zoccolilloa, J. Anal. Chim. Acta., 2002, 461, 97-108.

7 R. C. Wei, R. Wang, Q. F. Zeng, M. Chen and T. Z. Liu, J. Chromatogr. Sci., 2009, 47, 581-584.

8 U. T. Sireli, H. Ekici, H. Y. Can and A. Karagoz, J. Dairy Sci., 2012, 95, 602-608.

9 J. Draher, V. Pound and T. M. Reddy, J. Chromatogr. A., 2014, 1373, 106-113.

10 Q. Cao, H. Zhao, Y.-J. He, N. Ding and J. Wang, Anal. Chim. Acta, 2010, 675, 24-28.

11 X. L. Luo, A. J. Killard and M. R. Smyth, Electroanalysis, 2006, 18, 1131-1134.

12 R. N. Liang, R. M. Zhang and W. Qin, Sens. Actuators, B, 2009, 141, 544-550.

13 K. L. Ai, Y. L. Liu and L. H. Lu, J. Am. Chem. Soc., 2009, 131, 9496-9497.

14 R. Sundarmurugasan, M. B. Gumpu, B. L. Ramachandra, N. Nesakumar, S. Sethuraman, U. M. Krishnan and J. B. B. Rayappana, Sens. Actuators, B, 2016, 230, 306-313.

15 V. Bellas and M. Rehahn, Angew. Chem., Int. Ed., 2007, 46, 5082-5104.

16 G. R. Whittell and I. Manners, Adv. Mater., 2007, 19, 34393468.

17 Y. J. Ma, W. F. Dong, M. A. Hempenius, H. Möhwald and G. J. Vancso, Nat. Mater., 2006, 5, 724-729.

18 B. Y. Kim, E. L. Ratcliff, N. R. Armstrong, T. Kowalewski and J. Pyun, Langmuir, 2010, 26, 2083-2092.

19 J. Elbert, M. Gallei, C. Ruettiger, A. Brunsen, H. Didzoleit, B. Stuehn and M. Rehahn, Organometallics, 2013, 32, 5873-5878.

20 J. Isaksson, C. Tengstedt, M. Fahlman, N. Robinson and M. Berggren, Adv. Mater., 2004, 16, 316-320.

21 P. Li, H. Kang and N. Che, Polym. Int., 2015, 64, 1015-1022.

22 A. Q. Shi, J. Wang, X. W. Han, X. A. Fang and Y. Z. Zhang, Sens. Actuators, B, 2014, 200, 206-212.

23 C. Y. Neo, N. K. Gopalan and J. Y. Ouyang, J. Mater. Chem. A, 2014, 2, 9226-9235.

24 A. T. Lawal, Mater. Res. Bull., 2016, 73, 308-350.

25 H. Kong, C. Gao and D. Yan, J. Am. Chem. Soc., 2004, 126, 412-413.

26 B. Scheibe, E. Borowiak-Palen and R. J. Kalenczuk, Mater. Charact., 2010, 61, 185-191.

27 L. Stobinski, B. lesiak, L. K. Övér, J. Tóth, S. Biniak, G. Trykowski and J. Judek, J. Alloys Compd., 2010, 501, 77-84.

28 F. J. Xiao and Y. J. Luo, Adv. Mater. Res., 2011, 197, 1225-1230.

29 H. X. Wu, R. Tong, X. Q. Qiu, H. F. Yang, Y. H. Lin, R. F. Cai and S. X. Qian, Carbon, 2007, 45, 152-159.

30 A. Tanver, M. H. Huang and Y. J. Luo, RSC Adv., 2016, 6, 49101-49112.

31 T. A. Saleh, S. Agarwal and V. K. Gupta, Appl. Catal., B, 2011, 106, 46-53.

32 T. A. Saleh and V. K. Gupta, J. Colloid Interface Sci., 2012, 371, 101-106.

33 T. I. T. Okpalugo, P. Papakonstantinou, H. Murphy, J. McLaughlin and N. M. D. Brown, Carbon, 2005, 43, 153161. 
34 W. M. da Silva, H. Ribeiro, J. C. Neves, A. R. Sousa and G. G. Silva, J. Appl. Polym. Sci., 2015, 132, 42587.

35 E. J. Lawrence, G. G. Wildgoose, L. Aldous, Y. A. Wu, J. H. Warner, R. G. Compton and P. D. McNaughter, Chem. Mater., 2011, 23, 3740-3751.

36 Y. Peng, J. E. Lu, C. P. Deming, L. Chen, N. Wang, E. Y. Hirata and S. Chen, Electrochim. Acta, 2016, 211, 704-710.

37 L. P. M. De Leo, E. de la Llave, D. Scherlis and F. J. Williams, J. Chem. Phys., 2013, 138, 114707.

38 C. Nietzold, P. M. Dietrich, A. Lippitz, U. Panne and W. E. S. Unger, Surf. Interface Anal., 2016, 48, 606-610.

39 M. X. Zhang and J. B. Hu, Electroanalysis, 2013, 25, 780-786.

40 M. Senel, E. Cevik and M. F. Abasiyanik, Sens. Actuators, B, 2010, 145, 444-450.

41 D. Nkosi, J. Pillay, K. I. Ozoemena, K. Nounehcd and M. Oyamac, Phys. Chem. Chem. Phys., 2010, 12, 604-613.
42 Y. W. Pei, J. Travas-Sejdic and D. E. Williams, Langmuir, 2012, 28, 8072-8083.

43 J. L. Gong, F. C. Gong, G. M. Zeng, G. L. Shen and R. Q. Yu, Talanta, 2003, 61, 447-453.

44 H. R. Zare, M. Namazian and M. L. Coote, Electrochim. Acta, 2009, 54, 5353-5357.

45 C. M. Yu, W. Y. Ji, Y. D. Wang, N. Bao and H. Y. Gu, Nanotechnology, 2013, 24, 115502-115510.

46 S. Palanisamy, S. Sakthinathan, S. M. Chen and X. H. Liu, Carbohydr. Polym., 2016, 135, 267-273.

47 L. Hem, S. Khay, J. H. Choi, E. D. Morgan, A. M. A. El-Aty and J. H. Shim, Toxicol. Res., 2010, 26, 149-155.

48 K. Reybier, S. Zairi, N. Jaffrezic-Renault and B. Fahys, Talanta, 2002, 56, 1015-1020.

49 M. Ye, Y. Yu, X. He, L. Jiang and C. Wu, J. Shanghai Ocean Univ., 2010, 19, 189-194. 